\title{
The possible use of IBM-compatible computers and digital-to-analog conversion to assess children for reading disabilities and to increase their phonemic awareness
}

\author{
DAVID P. HURFORD \\ Pittsburg State University, Pittsburg, Kansas
}

\begin{abstract}
Hurford and Sanders (1990) and Hurford (1990) have been successful at employing digital-toanalog $(\mathrm{D} / \mathrm{A})$ conversion to remediate phonemic processing deficiencies in young disabled readers. The present study outlines how $\mathrm{D} / \mathrm{A}$ conversion might be used to identify students who are at risk for reading disabilities. A large sample of first-quarter first graders (227) was administered tests of reading (the Word Identification and Word Attack subtests of the Woodcock Reading Mastery Tests-Revised), a measure of intelligence (IQ according to the Peabody Picture Vocabulary Test-Revised), and two measures of phonemic processing (phonemic discrimination and phonemic segmentation). The phonemic processing measures were significantly related to the measures of reading $(p s<.0001$ ). Students assigned to at-risk and not-at-risk groups on the basis of their reading scores were significantly different on the phonemic processing measures and on IQ. No differences were due to age. After the data were reanalyzed with IQ as a covariate, only phonemic segmentation differentiated the two groups. Although phonemic discrimination may be less useful for identifying young at-risk students, it seems to help in the remediation of phonemic processing deficiencies. Phonemic discrimination training would be less effective were it not for $\mathrm{D} / \mathrm{A}$ conversion with personal computers.
\end{abstract}

Most children with learning disabilities have reading disabilities as their major difficulty. A large body of literature suggests that reading-disabled children are deficient in processing the smallest segments of spoken languagephonemes. Deficits in phonemic awareness have been implicated as a causal factor in reading-disabled children's inability to master beginning reading skills (Rozin \& Gleitman, 1977; Wagner \& Torgesen, 1987). A very important task for the beginning reader is to segment printed words into their respective phonemes and then to blend those sounds together to form words. This can be observed in beginning readers as they decipher words. Usually, they move their fingers very slowly as they form the sounds that the printed letters represent. It is as if the beginning reader must first "hear" himself or herself pronounce the sounds and blend them together before recognizing the word.

The child with reading disabilities is at a marked disadvantage if he or she does not understand the conceptual nature of the phoneme. The child will literally be unable to decipher the printed words into phonemes and thus will not be able to recombine the sounds to form words. The results of several studies support this view (e.g., Helfgott, 1976; Liberman, Shankweiler, Liberman, Fowler, \&

Correspondence should be addressed to David P. Hurford, Department of Psychology and Counseling, Pittsburg State University, Pittsburg, KS 66762.
Fischer, 1977; Zifcak, 1981); they suggest the inability to segment words into phonemes is a strong predictor of future reading disabilities. Others have argued more strongly that deficits in phonemic awareness are causative factors in reading disabilities (Wagner \& Torgesen, 1987).

Hurford and Sanders (1990) have examined the possibility that disabled readers are deficient in their phonemic awareness because they are simply unable to discriminate between phonemes. If the child with reading disabilities is unable to make discriminations among phonemes, then, theoretically, this deficit should prevent the disabled reader from being able to process phonemic information any further. It would seem that the ability to discriminate between phonemes should be a prerequisite to further processing. Hurford and Sanders's task consisted of two pairs of CV syllables presented auditorily. The first pair was a standard, in which the CV syllables were separated by varying intersyllable intervals (ISIs). The second pair (the comparison) followed 1,000 msec later and had either the same or a different combination of the two CV syllables (/bi/ ISI /di/ $1,000 \mathrm{msec} / \mathrm{di} / \mathrm{ISI} / \mathrm{di} /=$ different; $/ \mathrm{di} / \mathrm{ISI} / \mathrm{bi} / 1,000 \mathrm{msec} / \mathrm{di} / \mathrm{ISI} / \mathrm{bi} /=$ same). The participants were to make manual responses, striking a red key on the keyboard for same and a blue key for different.

Hurford and Sanders (1990) found that young (secondgrade) disabled readers were quite deficient in their ability to discriminate phonemes. Examination of the older (fourth-grade) disabled readers, who performed at levels 
that were not significantly different from those of secondgrade nondisabled readers, suggested that the phonemic discrimination deficit was a result of a delay in the development of phonemic discrimination ability. Unfortunately, even though the fourth-grade disabled readers had achieved a better mastery of phonemic discrimination, the other skills that were awaiting the development of phonemic discrimination and were necessary before the reading process could proceed were delayed as well. These disabled readers were still poor readers, even though they had acquired adequate phonemic discrimination ability.

In the second experiment, the reading-disabled children whose mean performance was greater than one standard deviation below the nondisabled readers' participated in the training. The training consisted of systematic experience with syllables that gradually became more complex in terms of the brevity and nature of the phonemic information that they conveyed. The intervention included three different phases that were presented on three different days. Procedurally, they were identical to the assessment except for two important differences: (1) the stimuli were manipulated in such a way that their complexity increased (a progression from vowel syllables to CV syllables that began with liquid consonants to $\mathrm{CV}$ syllables that began with plosive consonants), and (2) informative feedback occurred after every trial in which a smiley face appeared on the computer's CRT for $3 \mathrm{sec}$. The training began with vowel syllables that had very slow formant transitions, if any. The training then proceeded to CV syllables that began with liquid consonants. These syllables have transitions, but they resemble vowels in that the transitions are slow and the syllables are spoken with the vocal tracts open. The last phase of training included CV syllables that began with voiced plosives. These syllables have very brief transitions. The participants were to judge the similarity of syllables as the phonemic information became systematically more complex.

For a reading-disabled participant to move on to the next training phase, he or she had to make eight consecutive correct responses at the shortest possible ISI. Although the Experiment 1 analyses indicated that the manipulation of ISI had no effect on performance, the longer ISIs were used to introduce each phase, and the shortest ISIs were used to build in as much stimulus difficulty as possible during training.

Hurford and Sanders's (1990) most important finding was that disabled readers could be trained to improve their phonemic discrimination ability greatly $(p s<.0001)$. It could thus be concluded that phonemic discrimination is an underdeveloped skill in young disabled readers, and that this may be the reason why disabled readers do not adequately engage in the reading process. It is quite promising that disabled readers can be trained to improve their ability in phonemic discrimination.

Hurford (1990) used the same training program that was used in the Hurford and Sanders (1990) study to train disabled readers to improve their phonemic segmentation ability. Phonemic segmentation is an ability more closely tied to actual reading than phonemic discrimination is. As mentioned above, phonemic segmentation has been found to be highly predictive of later reading success. Hurford's (1990) results indicated that disabled readers who are deficient in phonemic segmentation can be trained to perform at significantly higher levels $(p<.004)$ after exposure to the phonemic discrimination intervention.

Hurford and Sanders (1990) and Hurford (1990) used IBM-compatible computers equipped with digital-toanalog (D/A) conversion boards (Qua Tech, ADM-ONE). These boards permit precise control over the presentation of the phonemic stimuli and provide a simple way to assess phonemic discrimination ability. The children were told that they would play "computer games" in which they would hear speech sounds.

The phonemic discrimination task was developed so that trial presentation could be strictly controlled. In many studies designed to assess phonemic discrimination or identification, the phonemic information is presented by means of audio tape (e.g., Godfrey, Syrdal-Lasky, Millay, $\&$ Knox, 1981). Although this procedure is appropriate for assessment, it makes training very difficult. Training requires an interactive component that is not possible when the stimuli are recorded on audio tape. For phonemic discrimination training to be effective, reinforcement must occur immediately after correct responding, the experimenter must be able to change task demands as performance improves, and there must be an ongoing analysis of the correct presentation of the stimuli. These requirements are all satisfied with the use of IBM-compatible computers equipped with D/A data-acquisition cards. Interestingly, the students who were involved in the training studies (Hurford, 1990; Hurford \& Sanders, 1990) enjoyed the task. Holding the attention of young disabled readers is necessary if training is to be successful, and the game-like format of the computer training was more than adequate to ensure active participation.

Once the stimuli had been digitized and edited (through computer-assisted phonemic display and editing programs), it was necessary to measure duration of the stimuli and the ISIs accurately. This was done with an oscilloscope (Tektronix Digital Oscilloscope, Model 2430) and with programmable digital output.

The intervention increased the disabled readers' ability to discriminate between phonemes and to segment words into phonemes. Both processes are important precursors to success at reading. If students who have difficulty processing phonemes can be identified very early in their academic careers, it might be possible to train them to overcome their phonemic awareness deficits and to engage in reading at age-appropriate times. Through the use of computer technology, it is presently possible to assess reading-disabled children's levels of phonemic awareness.

The present study involved the first data-collection period of a longitudinal study designed to track the phonemic processing skills of young beginning readers. Firstquarter first graders were given tests of phonemic processing, word identification, phonic skills, and intelligence. 
It was hoped that these data would successfully predict the students' subsequent levels of reading achievement, which were to be tested 1 year later. If the phonemic processing tasks could identify children who were at risk for reading disabilities, it might then become possible to strengthen many young at-risk prereaders' phonemic processing skills before such inadequate abilities would create problems for them.

\section{METHOD}

\section{Participants}

The sample consisted of 227 first-quarter first graders from each of the five elementary schools in a mediumsized midwestern school district (the city's population was approximately 18,000 ). This sample represented all but 3 of the 230 first graders in the school district (see Table 1). Of the 3 not included in this study, 2 failed the audiometric exam, and the 3rd spoke little English. The average first grader at the time of this testing was 6 years and 8.5 months old.

\section{Apparatus}

Five computer systems with D/A conversion boards were used to simultaneously collect data in each of the five elementary schools. Four of the five computers were AT-compatible (12-MHz operating speed) while the fifth was XT-compatible (4.77-MHz operating speed). Although there were differences in the operating speeds of the computers, equivalency in the digital output was possible through programming.

The D/A conversion modules (Qua-Tech; DM12-ONE) were single-channel 12-bit modules that used a DAC80 D/A converter chip with a conversion speed of $3 \mu \mathrm{sec}$. The D/A conversion modules were mounted on a 72 channel digital input/output (I/O) expansion card (QuaTech; PXB-721). The PXB-721 has three 8255 programmable peripheral interface chips, each providing 24 lines of I/O. Only one interface chip was used for the D/A output. The D/A boards (DM12-ONE mounted on the PXB721) were supported with LABSTAR software, which is an assembly language driver in which the commands were called from BASIC (commands are also callable from C, FORTRAN, and Turbo PASCAL).

The analog signal exiting the D/A conversion was amplified with a stereo amplifier (Realistic SA 150) and heard over Realistic Nova 16 stereo headphones at a comfortable listening level.

A Beltone audiometer (Model 112) was used to administer the audiometric exam at frequencies in the range of speech $(500,1000,2000$, and $4000 \mathrm{~Hz}$; all were at $25 \mathrm{~dB})$.

\section{Tasks}

The phonemic discrimination and segmentation tasks were the same as those used in the Hurford and Sanders (1990) and Hurford (1990) studies and were used to assess phonemic processing skills. The Word Identification and Word Attack subtests of the Woodcock Reading
Mastery Tests-Revised (Woodcock, 1987) were used to measure the ability of the students to read single words and to use phonics rules, respectively. The Peabody Picture Vocabulary Test-Revised (PPVT-R; Dunn, 1981) was used to assess the students' receptive vocabulary.

\section{Procedure}

The audiometric exam was administered 1 week prior to data collection.

The tasks were presented in three completely counterbalanced blocks. The first block consisted of the phonemic discrimination task, the second block consisted of the PPVT-R, and the third block consisted of the word identification, word attack, and phonemic segmentation tasks (in that order). Blocks were constructed on the basis of the estimated time for completion (each block was estimated to take approximately $10 \mathrm{~min}$ ). Three participants were assessed at the same time at three separate stations representing the three different blocks. After completion of one of the blocks, the participants had a short break; they were then rotated to another block until they had completed all three blocks.

The phonemic discrimination task was preceded by the instructional training task, which essentially taught each participant how to perform the phonemic discrimination task (see Hurford \& Sanders, 1990). This task gradually moves the participant from making same or different judgments based on visual information to judgments based solely on phonemic information. Because of the task's complexity, it was necessary to ensure that the participants understood the task before it began.

The phonemic discrimination task in the present study involved three different ISIs $(10,80$, and $160 \mathrm{msec})$, for a total of 72 trials.

The phonemic segmentation task (Hurford, 1990) was composed of $12 \mathrm{CVC}$ words and $12 \mathrm{CVC}$ nonwords. The words were chosen according to their recognizability for young children, and the nonwords were created to follow orthographic rules.

\section{RESULTS AND DISCUSSION}

The means and standard deviations are displayed in Table 1 for each of the measures. The mean receptive vo-

Table 1

Mean Age and Test Scores, with Standard Deviations, for the First Graders

\begin{tabular}{lrr}
\hline \multicolumn{1}{c}{ Variable } & $M$ & \multicolumn{1}{c}{$S D$} \\
\hline Age (in months) & 80.5 & 4.9 \\
IQ & 99.5 & 14.6 \\
Segmentation & 37.1 & 30.8 \\
Discrimination & 61.9 & 14.2 \\
Identification* & 9.2 & 11.3 \\
Attack* & 2.8 & 4.7 \\
Identification $\dagger$ & 88.5 & 14.7 \\
Attack $\dagger$ & 82.3 & 14.9 \\
\hline
\end{tabular}

Note-IQ was measured with the Peabody Picture Vocabulary TestRevised (Dunn, 1981). *Raw score. †Standardized score. 
cabulary IQ score was 99.5 , with a standard deviation of 14.6. These values match very well the mean and standard deviations for the PPVT-R (100 and 15, respectively), as do the standard deviations for the Word Identification and Word Attack standard scores. The means are lower than would be expected, but, it should be kept in mind that these students had just begun first grade and were just beginning to engage in the beginning reading process. The raw scores for the Word Identification and the Word Attack tasks reflect the actual number of words and nonwords read, respectively.

The beginning first graders performed quite poorly on the phonemic discrimination and phonemic segmentation tasks, which was not expected. It seems reasonable to suggest, however, that the participants' phonemic processing skills were in general underdeveloped. As the phonemic processing system matures, the performance on these two measures of phonemic processing should improve. This argument is strengthened when these scores are compared with those of second-grade children with reading disabilities. Second-grade reading-disabled children's phonemic processing abilities are less mature than those of their nondisabled grademates. These skills will eventually become mature, and most of the disabled readers will eventually be able to process phonemic information adequately. The performances of the secondgrade children with reading disabilities in the Hurford and Sanders (1990) and the Hurford (1990) studies were very similar to the performance of the first-grade children in the present study (see Table 2). The second graders were all assessed during the end of their second-grade year, so that there is approximately a $1 \frac{112}{2}$ years' difference between the assessment of the second-grade disabled readers and the assessment of the first-grade students in the present study. The results of the present study support the hypotheses that disabled readers are developmentally delayed in their phonemic processing skills and that the phonemic processing skills of beginning first graders is somewhat underdeveloped. It is at this point (at an age of 6 years or so) that many individuals begin to develop phonemic awareness skills (Liberman, 1989). It is expected that by the second time of measurement, the phonemic processing skills will be much more developed and the scores will thus be significantly better.

The next concern in the present study was to determine whether the performance on the phonemic processing

\section{Table 2}

Comparison of the Means from Second-Grade Disabled Readers and First-Quarter First Graders on the Phonemic Discrimination and Segmentation Tasks

\begin{tabular}{lcc}
\hline \multirow{2}{*}{ Group } & \multicolumn{2}{c}{ Task } \\
\cline { 2 - 3 } & Discrimination & Segmentation \\
\hline Second-grade reading disabled & 69.7 & 38.7 \\
First graders & 61.9 & 37.1 \\
\hline
\end{tabular}

Note-The discrimination and segmentation scores for the second-grade disabled readers are from Hurford and Sanders (1990) and Hurford (1990), respectively.
Table 3

Correlation Coefricients for the First Graders

\begin{tabular}{lccc}
\hline & Discrimination & Segmentation & Reading \\
\hline Discrimination & .36 & .37 \\
Segmentation & & .65 \\
Reading & & \\
\hline Note $-p<.0001$. Reading $=$ average of Word Identification and Word
\end{tabular}
Attack subtests.

tasks was related to performance in the reading of words and nonwords. The reading scores were an average of each student's score on the Word Identification and Word Attack subtests. The correlations between phonemic discrimination, phonemic segmentation, and the reading scores can be seen in Table 3. All of these variables were significantly correlated. In addition, the results of a multiple regression $[F(2,224)=87.2, p<.0001$, with an $R^{2}$ of .44] indicated that phonemic discrimination and segmentation could account for $44 \%$ of the variance of beginning-reading/prereading first graders. Poor performance on phonemic discrimination and segmentation tasks might help predict early phonemic processing difficulties and thus of early reading problems. The assessment of first-grade children's phonemic processing abilities, followed by training in phonemic processing, might enable a large number of young readers who might otherwise become reading-disabled to read successfully.

Of further interest was whether a group of at-risk students could be identified on the basis of their reading scores. Students who had reading scores of less than 1 were included in the at-risk group. Although this "at-risk" group is a somewhat artificial construct since there are no "at-risk" reference scores with actual reading-disabled children, it was thought that this conceptualization might be useful. Forty children (16.7\% of the sample) were included in the at-risk group. This percentage may be somewhat higher than would be expected, although the actual incidence of learning disabilities has been reported from as low as $2.6 \%$ (Farnham-Diggory, 1978) to as high as $41 \%$ (Rubin \& Balow, 1971). For the purposes of training, it would be more conservative to have more false positives than false negatives among at-risk children. A 2 (group) $\times 2$ (gender of the student) multivariate analysis of variance was then performed with the dependent measures of phonemic segmentation, phonemic discrimination, IQ (PPVT-R), and age (in months). Only the effect of group (at risk vs. not at risk) was significant [Wilk's Lambda, $F(4,220)=9.33, p<.0001$ ]. Neither the gender of the student nor the interaction of group and gender even approached significance $(p>.65$ and $p>.53$, respectively). The univariate analyses indicated that there were significant differences between the at-risk and the not-at-risk students on phonemic segmentation $(p<.0001)$, phonemic discrimination $(p<.035)$, and IQ $(p<.0001)$. (See Table 4.) No differences were due to age $(p>.73)$. Because of the significant difference in IQ between the at-risk and the not-at-risk students, the data were reanalyzed with IQ as a covariate. The two 
Table 4

Mean Scores on the Phonemic Segmentation and Phonemic Discrimination Tasks, and Mean IQ and Age by Group

\begin{tabular}{lcc} 
& \multicolumn{2}{c}{ Group } \\
\cline { 2 - 3 } & At Risk & Not at Risk \\
\hline Phonemic segmentation & 11.7 & 42.5 \\
Phonemic discrimination & 57.1 & 62.9 \\
IQ & 91.6 & 101.2 \\
Age (in months) & 80.2 & 80.5 \\
\hline
\end{tabular}

Note-IQ was measured with the Peabody Picture Vocabulary TestRevised (Dunn, 1981)

groups were no longer different on phonemic discrimination, but they remained significantly different on phonemic segmentation $(p<.0001$, with least squares means of 16.8 and 41.1 on the phonemic segmentation task and 59.4 and 62.4 on the phonemic discrimination task for the at-risk and not-at-risk students, respectively). Although there were differences in IQ between the at-risk and the not-at-risk students, the mean IQ for the at-risk students was still within normal limits. It may be that phonemic processing training could significantly improve their performance as well.

\section{CONCLUSIONS}

The use of computers equipped with D/A conversion has allowed young disabled readers to be successfully trained on phonemic processing skills. The phonemic discrimination training has been used to improve the phonemic discrimination ability of young disabled readers (Hurford \& Sanders, 1990), as well as their phonemic segmentation abilities (Hurford, 1990), significantly. Hurford and Sanders hypothesized that phonemic discrimination was a prerequisite to phonemic processing capabilities. It may be that it is just another means for measuring phonemic processing and that its real value is that it can be used to improve other related phonemic processing skills that are highly related to reading success. The results of the present study indicate the powerful relationship that exists between phonemic processing and reading skills.

The technology of D/A conversion has presented a useful and enjoyable way for disabled readers (and possibly at-risk students) to interact with a carefully controlled phonemic environment. As a result of this interaction, the disabled readers have been able to improve their phonemic processing abilities. Although considerably more work is necessary, it may eventually be possible to prevent many young children from ever experiencing reading disabilities because of poor phonemic processing skills.

\section{REFERENCES}

Dunn, L. M. (1981). Peabody Picture Vocabulary Test-Revised. Circle Pines, MN: American Guidance Service, Inc.

FARNHAM-Diggory, S. (1978). Learning disabilities: A psychological perspective. Cambridge, MA: Harvard University Press.

Godfrey, J. J., Syrdal-Lasky, A. K., Millay, K. K., Knox, C. M. (1981). Performance of dyslexic children on speech perception tests. Journal of Experimental Child Psychology, 32, 401-424.

HelfGott, J. A. (1976). Phonemic segmentation and blending skills of kindergarten children: Implications for beginning reading acquisition. Contemporary Educational Psychology, 1, 157-169.

HuRford, D. P. (1990). Training phonemic segmentation ability with a phonemic discrimination intervention in second- and third-grade children with reading disabilities. Journal of Learning Disabilities, 23, 564-569.

HuRford, D. P., \& SANDERs, R. E. (1990). Assessment and remediation of a phonemic discrimination deficit in reading disabled secondand fourth-graders. Journal of Experimental Child Psychology, 50, 396-415.

Liberman, A. M. (1989). Reading is hard just because listening is easy. In C. von Euler (Ed.), Wennergren Intemational Symposium series: Brain and reading. Basingstoke, U.K.: Macmillan.

Liberman, I. Y., Shankweiler, D., Liberman, A. M., Fowler, C., a Fischer, F. W. (1977). Phonetic segmentation and recoding in the beginning reader. In A. S. Reber \& D. L. Scarborough (Eds.), Toward a psychology of reading: The proceedings of the CUNY conference (pp. 207-225). Hillsdale, NJ: Erlbaum.

RoziN, P., \& Gleitman, L. R. (1977). The structure and acquisition of reading: II. The reading process and the acquisition of the alphabetic principle. In A. S. Reber \& D. L. Scarborough (Eds.), Toward a psychology of reading: The proceedings of the CUNY conference (pp. 55-141). Hilisdale, NJ: Erlbaum.

Rubin, R., BALOW, B. (1971). Learning and behavior disorders: A longitudinal study. Exceptional Children, 38, 293-300.

WAGNER, R. K., TORGESEN, J. K. (1987). The nature of phonological processing and its causal role in the acquisition of reading skills. Psychological Bulletin, 101, 192-212.

Wooncock, R. W. (1987). Woodcock Reading Mastery Tests-Revised. Circle Pines, MN: American Guidance Service, Inc.

Zifcak, M. (1981). Phonological awareness and reading acquisition. Contemporary Educational Psychology, 6, 117-126. 